\title{
COMMUNITY-BASED "PASUNG" RELEASE FRAMEWORK TO STRENGTHEN PASUNG HANDLING SYSTEM ON PEOPLE WITH PSYCHOSIS
}

\author{
Heni Dwi Windarwati1,2), Budi Anna Keliat3), Raden I. Ismail4), Adang \\ Bachtiar5) \\ 1) Department of Mental Nursing, Faculty of Medicine, Universitas Brawijaya \\ 2)Doctoral Program in Universitas Indonesia \\ 3) Department of Mental Nursing, Faculty of Nursing, Universitas Indonesia \\ 4) Department of Psychiatry, Faculty of Medicine, Universitas Indonesia \\ 5)Deparment of Public Health, Faculty of Public Health, Universitas Indonesia
}

\begin{abstract}
Background: Indonesia has the highest level of pasung for people with psychosis in the world. Nearly 60 thousand people with psychosis are illegally detained ('pasung') in family homes. Communities and families have a large role in developing global strategies through the availability of a community-based pasung release framework. The purpose of this study is to develop a pasung release framework that can be tested in accordance with the culture of the Indonesian people to strengthen local mental health services in the release of income.

Subjects and Method: This was a mixed method study carried out in East Java, Indonesia. This study consisted of 3 phases: (1) Explored community involvement through a systematic review of the available evidence. A total of 25 people consisting of health workers, families, communities, and people with schizophrenia, were interviewed in this study; (2) Identified stakeholders as well as the steps and their respective roles used in developing the foundation of the community-based pasung release framework. To explored the potential use of community involvement in the release of pasung in Indonesia and identify priorities for a framework that is culturally appropriate; and (3) Produced a framework for community involvement in pasung release to be used in Indonesia by synthesizing evidence from all phases.

Results: Community involvement was the best way to realize a pasung release framework that was in accordance with Indonesian culture. Mental health services in pasung release involving community elements in low and middle-income countries could overcome the burden of mental health conditions through the development of communitycentered care models. However, such an approach had not been developed in Indonesia.
\end{abstract}

Conclusion: Community-based pasung release framework can be tested for use in mental health services, especially pasung release in people with psychosis in Indonesia.

Keywords: pasung release, people with psychosis, pasung release framework, mental health

\section{Correspondence:}

Heni Dwi Windarwati. Department of Mental Nursing, Faculty of Medicine, Universitas Brawijaya/ Universitas Indonesia. Email: hewinda80@gmail.com. Mobile: 082232641330. 